\title{
QUEEN'S
UNIVERSITY
BELFAST
}

\section{Additive multiple predator effects of two specialist paradiaptomid copepods towards larval mosquitoes}

Cuthbert, R. N., Dalu, T., Wasserman, R. J., Weyl, O. L. F., Froneman, P. W., Callaghan, A., \& Dick, J. T. A. (2019). Additive multiple predator effects of two specialist paradiaptomid copepods towards larval mosquitoes. Limnologica, 79, [125727]. https://doi.org/10.1016/j.limno.2019.125727

\section{Published in:}

Limnologica

\section{Document Version:}

Peer reviewed version

Queen's University Belfast - Research Portal:

Link to publication record in Queen's University Belfast Research Portal

\section{Publisher rights}

Copyright 2019 Elsevier.

This manuscript is distributed under a Creative Commons Attribution-NonCommercial-NoDerivs License

(https://creativecommons.org/licenses/by-nc-nd/4.0/), which permits distribution and reproduction for non-commercial purposes, provided the author and source are cited.

\section{General rights}

Copyright for the publications made accessible via the Queen's University Belfast Research Portal is retained by the author(s) and / or other copyright owners and it is a condition of accessing these publications that users recognise and abide by the legal requirements associated with these rights.

Take down policy

The Research Portal is Queen's institutional repository that provides access to Queen's research output. Every effort has been made to ensure that content in the Research Portal does not infringe any person's rights, or applicable UK laws. If you discover content in the Research Portal that you believe breaches copyright or violates any law, please contact openaccess@qub.ac.uk. 
1 Research Article

\section{Additive multiple predator effects of two specialist paradiaptomid}

3

4

5 Ross N. Cuthbert ${ }^{1,2,3, *}$, Tatenda Dalu ${ }^{4,5}$, Ryan J. Wasserman ${ }^{6,5}$, Olaf L. F. Weyl ${ }^{2}$, P.

6 William Froneman ${ }^{7}$, Amanda Callaghan ${ }^{3}$, Jaimie T. A. Dick ${ }^{1}$

7

$8{ }^{1}$ Institute for Global Food Security, School of Biological Sciences, Queen's University

9 Belfast, Belfast BT9 5DL, Northern Ireland

\section{copepods towards larval mosquitoes}

${ }^{2}$ DST/NRF Research Chair in Inland Fisheries and Freshwater Ecology, South African Institute for Aquatic Biodiversity, Makhanda 6140, South Africa

${ }^{3}$ Ecology and Evolutionary Biology, School of Biological Sciences, University of Reading,

Harborne Building, Reading RG6 6AS, England

${ }^{4}$ Department of Ecology and Resource Management, University of Venda, Thohoyandou 0950, South Africa

${ }^{5}$ South African Institute for Aquatic Biodiversity, Makhanda 6140, South Africa

${ }^{6}$ Department of Biological Sciences and Biotechnology, Botswana International University of Science and Technology, Palapye, Botswana

${ }^{7}$ Department of Zoology and Entomology, Rhodes University, Makhanda 6140, South Africa 


\section{Abstract}

Interactions between multiple predators can profoundly affect prey risk, with implications for prey population stability and ecosystem functioning. In austral temporary wetlands, arid-area adapted specialist copepods are key predators for much of the hydroperiod. Limited autoecological information relating to species interactions negates understandings of trophic dynamics in these systems. In the present study, we examine multiple predator effects of two key predatory paradiaptomid copepods which often coexist in austral temporary wetlands, Lovenula raynerae Suárez-Morales et al., 2015 and Paradiaptomus lamellatus Sars, 1985. Predation rates towards larval mosquito prey across different water depths are quantified. Using a comparative functional response approach, individual L. raynerae exhibited significantly higher feeding rates than $P$. lamellatus, characterised by higher attack rates, shorter handling times and higher maximum feeding rates. Increasing water depth tended to negatively affect prey consumption, particularly for $L$. raynerae. Interspecific multiple predator consumption combined additively, and thus prey risks were well-predicted from consumption rates by individual paradiaptomid copepod species, irrespective of water depth. Our results suggest that increasing copepod predator diversity in austral temporary wetland ecosystems additively heightens prey risk across different water volumes, and may help to regulate disease vector mosquito populations. Therefore, the numerical extent, phenology and diversity of predator hatching events during the hydroperiod may substantially mediate interaction strengths in these ecosystems.

\section{Keywords}

zooplankton; temporary wetland; predator-predator interaction; larval mosquitoes; water depth; functional response 


\section{Introduction}

47

Predator-prey interaction strengths are pervasive in their influence on community composition within ecosystems (Paine, 1980; Sih et al., 1985; Wasserman et al., 2013). However, predator species rarely exist in isolation, with an array of trophic and non-trophic interactions known to embed predators and their prey in complex ecological networks (Thompson, 2005; Sentis et al., 2017; Veselý et al., 2017, 2019). For instance, predators do not only interact with their prey, but may also interact with one another as they compete for shared resources (Polis et al., 1989; Johnson et al., 2009; Wasserman et al., 2016a; Sentis and Boukal, 2018). These interactions are recognised as important components that contribute to outcomes of predator-prey interactions by mediating levels of prey risk (Sih et al., 1998; Bolker et al., 2003; Griffen, 2006). In turn, such processes may impart stability to prey populations if, for example, predation risk is reduced. Therefore, quantifications of multiple predator effects are important for robust food web models (McCoy et al., 2012; Sentis and Boukal, 2018), and for understanding the implications of predator extirpation implications within ecosystems. Furthermore, such interactions may have ecological and even economic implications, for instance in agroecosystems pest species regulation by multiple natural enemies (Losey and Denno, 1998), or the regulation of pathogen and parasite vectors such as mosquitoes (Cuthbert et al., 2019b).

Multiple predator effects can manifest in a number of ways in a prey risk context, and there are many examples where predator impacts on prey do not combine additively (Beddington, 1975; Soluk, 1993; Sih et al., 1998; Barrios-O’Neill et al., 2014). In this context, predation risk can either be greater (prey risk enhancement) or lesser (prey risk reduction) than that expected based on additivity among predators (Griffen, 2006). A functional response approach is often used to quantify the density-dependence of interaction strengths through examination of the relationship between resource availability and resource consumption 
71 (Holling, 1959). This density-dependence can, theoretically, have profound implications for the stability of lower trophic groups within ecosystems, with hyperbolic Type II functional responses regarded as destabilising for prey populations whilst, conversely, sigmoid Type III functional responses may allow for stability of prey through low-density refuge effects (Hassell, 1978). Despite the importance of density-mediated effects for predator-prey dynamics, relatively few studies have examined multiple predator effects using a functional response approach (Soluk, 1993; Losey and Denno, 1998; Lampropoulos et al., 2013; Barrios-O'Neill et al., 2014; Wasserman et al., 2016a; Sentis et al., 2017; Veselý et al., 2017, 2019; Mofu et al., 2019). Furthermore, the limited work which has been done has produced equivocal results, with examples of synergism, additivity and antagonism displayed among predators. This demonstrates the complexity and system-specificity of predator-predator exchanges that impedes broad-scale extrapolations across taxonomic groups and habitat types.

Predation has a marked influence on zooplankton communities in aquatic ecosystems (Lynch, 1979; Neill, 1990; Wasserman et al., 2013). In temporary aquatic ecosystems, predation pressure is transient owing to successive wet and dry periods coupled with temporal variability in colonisation dynamics (Wasserman et al., 2016b, 2018). In the early-mid stages of hydroperiod, internal recruitment of zooplankters from resting egg banks drives community composition and biotic interactions (Brendonck and De Meester, 2003; O’Neill and Thorp, 2014; Cuthbert et al., 2019c). Higher-order predators, such as hexapods, are externally recruited later (O’Neill and Thorp, 2014; Wasserman et al., 2016b). Temporary ponds can, accordingly, contain substantive and diverse abundances of zooplankton shortly after wet phase initiation (O’Neill and Thorp, 2014), and some hatching copepods are predatory (Wasserman et al., 2016b; Cuthbert et al., 2018a). Given that more than one predatory copepod species often emerges from dormant eggs in these ecosystems (Day et al., 
2001; Wasserman et al., 2016b), predator-predator exchanges may have implications for colonist prey. In the present study, we examined emergent multiple predator effects among key pioneer zooplankters which inhabit austral temporary aquatic ecosystems.

Two pioneering paradiaptomid copepod species numerically dominate temporary wetland ecosystems in the early stages of hydroperiod in the Eastern Cape province of South Africa, Lovenula raynerae Suárez-Morales, Wasserman and Dalu, 2015 (Suárez-Morales et al., 2015) and Paradiaptomus lamellatus Sars, 1985. Both species belong to Paradiaptomidae, a temporary-water adapted African subfamily (Day et al., 2001). These copepod species are atypically large (4 - $5 \mathrm{~mm}$ ) and predatory, and their simultaneous occurrence in high abundances drives high potential for interspecific predator-predator exchanges. Furthermore, the two species appear to occupy distinct areas of the water column, with L. raynerae an active forager in the open water, whilst $P$. lamellatus is an ambush hyperbenthic predator (Cuthbert, pers. obs.). Given such spatial differences in habitat use, alongside inherent variations in water volumes in temporary wetlands over the hydroperiod, it is possible that differences in water depth further mediate interactions between these predatory species. For example, in shallower systems, predator-predator encounters may be intensified due to spatial overlaps in habitat use between predator species (see also Schmitz, 2007). In turn, this may exacerbate or dampen emergent multiple predator effects. Furthermore, search area alone is known to modulate predator-prey interactions, and this can be readily represented in laboratory studies through systematic alterations to experimental arena size or volume (Uiterwaal and DeLong, 2016).

In the present study, we quantify emergent multiple predator effects between $L$. raynerae and P. lamellatus towards common larval mosquito prey, which also externally colonise temporary pond environments during wet phases. We employ a comparative functional response approach to elucidate density-dependence of multiple predator interactions and 
examine whether differences in water depth further alter the nature of these interactions. As relatively little information is available on the trophic ecology of austral temporary wetlands, the present study provides valuable insights on predator-prey relationships in these food webs, including for the regulation of pest and vector species such as mosquitoes.

\section{Materials and methods}

\subsection{Animal collection and maintenance}

Gravid adult females of Lovenula raynerae (mean length \pm 1 SE: $5.02 \pm 0.07 \mathrm{~mm}$ ) and Paradiaptomus lamellatus $(4.00 \pm 0.07 \mathrm{~mm})$ were collected from a temporary pond near the

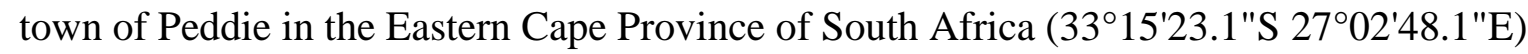
by pulling a $64 \mu \mathrm{m}$ mesh zooplankton net through the water column. Copepods were transported in source water to a controlled environment (CE) room in the Department of Zoology and Entomology, Rhodes University, Makhanda and housed in separate $5 \mathrm{~L}$ aquaria containing $100 \mu \mathrm{m}$ mesh-strained source water according to species. The CE room was maintained at $21 \pm 1{ }^{\circ} \mathrm{C}$ and under a 14:10 light and dark photoperiod regime. Copepods were starved for $24 \mathrm{~h}$ prior to experimentation. The prey, second instar larval Culex pipiens complex mosquitoes were cultured from egg rafts collected from container-style habitats on the University campus, and reared to the desired size class $(2.71 \pm 0.11 \mathrm{~mm})$ in the same CE room on a diet of rabbit food pellets (Agricol, Port Elizabeth).

\subsection{Experimental design}


144 Consumption (i.e. numbers of prey killed or eaten) by individuals or interspecific pairs of the two predatory copepods (i.e. L. raynerae; P. lamellatus; L. raynerae + P. lamellatus) was quantified towards five densities of the larval mosquito prey $(2 ; 4 ; 8 ; 16 ; 32)$ and under two water depth (i.e. volume) treatments $(40 \mathrm{~mL} ; 80 \mathrm{~mL})$ in a factorial design. The associated water depths were 1.6 and $3.3 \mathrm{~cm}$ at $40 \mathrm{~mL}$ and $80 \mathrm{~mL}$ volumes, respectively. In the $\mathrm{CE}$ room, mosquito prey were introduced under allotted densities into glass aquaria $(5.6 \mathrm{~cm} \mathrm{dia.)}$ containing the allocated water depth in a randomised array. Prey were allowed to settle for 2 h, after which a pre-designated copepod predator treatment was introduced. Predators were

\subsection{Statistical analyses}

Prey consumption (i.e. numbers of prey killed) was examined with respect to predator (3 levels), depth (2 levels) and density (5 levels), and their two- and three-way interactions, in a Poisson generalised linear model with log link. Model averaging via a second-order derivation of Akaike's information criterion (AICc) was used to select predictors which minimised information loss (Burnham and Anderson, 2002). The initial tested model included all fixed effects and their interaction terms. Model comparisons were made using 
interchangeable (Burnham and Anderson, 2002). The relative variable importance (RVI) of predictors was also calculated based on the sum of AICc model weights, whereby predictors with RVI close to 1 are considered to yield high importance (Bartoń, 2016). Analysis of deviance was used to discern effect sizes and significance levels of predictors in the top model(s) (Fox and Weisberg, 2011), and Tukey comparisons were used post-hoc based on estimated marginal means (Lenth, 2018).

Functional response analyses were undertaken phenomenologically (see Alexander et al., 2012). Logistic regression was used to distinguish between functional response types (i.e. type II or type III) among predator and depth treatments. Here, a significantly negative firstorder term indicates a type II functional response, whilst a significantly positive first-order and significantly negative second-order term indicates a type III functional response (Trexler et al., 1988; Juliano, 2001). Owing to the non-replacement of prey during the experiment, Rogers' random predator equation was employed (Rogers, 1972):

$$
N_{e}=N_{0}\left(1-\exp \left(a\left(N_{e} h-T\right)\right)\right)
$$

where $N_{e}$ is the number of prey eaten, $N_{0}$ is the initial density of prey, $a$ is the attack rate, $h$ is the handling time and $T$ is the total experimental period. The Lambert $\mathrm{W}$ function was implemented due to the recursive nature of the Random predator equation (Bolker, 2008).

Given that we did not empirically measure these parameter estimates, attack rates and handling times were not considered mechanistically, but were instead used for comparative purposes among the factorial experimental treatment groups (see Jeschke et al., 2002). Where evidence for a given functional response type (i.e. type II or type III; see above) was equivocal, a generalised form of the random predator equation with scaling exponent $q$ was fit (see Real, 1977; Vucic-Pestic et al., 2010), and suitability of each model compared based 
on $\triangle \mathrm{AICc}$. The use of the scaling exponent allows functional responses to be quantified in a continuous manner between types II and III.

To quantify emergent multiple predator effects, we followed McCoy et al. (2012) and Sentis and Boukal (2018) and employed a population dynamic approach. This method has been shown to be more robust than other commonly-used approaches for simulating multiple predator effects in additive experimental designs (Sentis and Boukal, 2018). We generated predictions of consumption in paired copepod groups based on the $a$ and $h$ estimates from the single predator treatments for both species and water depths:

$$
\frac{d N}{d t}=-\sum_{i=1}^{n} f_{i}(N) P_{i}
$$

where $N$ is the prey population density, $P_{i}(i=1,2, \ldots, n)$ are the population densities of predators $i$ and $f_{i}(N)$ is the functional response of predator $i$ (i.e. Eqn. 1). These predictions were subsequently compared to actual experimental observations of paired predator consumption to quantify multiple predator effects. Predictions were made under all experimental prey densities, for the entire experimental duration. Global sensitivity analysis was used to generate $95 \%$ confidence intervals based on the $a$ and $h$ estimates, and their standard errors and covariance-variance matrices, from the single predator treatments. A Latin hypercube sampling algorithm was then used to generate parameter sets over time (Soetaert and Petzoldt, 2010). For both predicted and observed functional responses, $95 \%$ confidence intervals were generated from $2.5 \%$ and $97.5 \%$ prey survival quantiles. Lower confidence interval limits were capped at 0 . Functional responses were then compared across prey densities on the basis of confidence interval overlaps. Statistical analyses were performed using R v3.5.1 (R Core Development Team, 2018). 
Two models with $\triangle \mathrm{AICc} \leq 2$ were identified, and neither contained interaction terms. The predator and density terms were retained in both top models (both RVI $=1.00$ ), whilst depth was present in one $(\mathrm{RVI}=0.62)$. All interaction terms were relatively unimportant (all $\mathrm{RVI} \leq$ 0.06) and thus removed from the final model of prey mortality from consumption. Prey consumption differed significantly according to the predator treatment $\left(\chi^{2}=109.30, \mathrm{df}=2, p\right.$ < 0.001) (Fig. 1). Paradiaptomus lamellatus killed significantly fewer prey than L. raynerae or paired predator treatments (both $p<0.001$ ). Differences between $L$. raynerae and paired predator groups were not statistically clear $(p=0.94)$. Numbers of prey killed increased significantly with density $\left(\chi^{2}=152.15, \mathrm{df}=2, p<0.001\right)$. Whilst increasing depth tended to reduce consumptive prey mortality (Fig. 1$)$, the effect was not statistically clear $\left(\chi^{2}=3.18\right.$, df $=1, p=0.07)$.

Evidence for type II functional responses was displayed under all predator treatments (Table 1). Whilst single $P$. lamellatus did not display a significantly negative first-order term, the random predator equation provided a better fit than in the non-fixed presence of scaling exponent $q$ under both water depths (both $\triangle \mathrm{AICc}>2$ ). Attack rates were inclined to be higher, handling times lower and thus maximum feeding rates greater for L. raynerae compared to P. lamellatus at the shallower water depth (Table 1). Increasing water depths generally lengthened handling times of L. raynerae, yet reduced those of P. lamellatus, resulting in more similar maximum feeding rates at the higher depth between predator species treatments between water depths. 
239 At the shallow water depth (Fig. 2a), functional response confidence intervals tended to diverge at low-intermediate prey densities, suggesting significant differences in feeding rates in favour of L. raynerae. Multiple predator functional responses were well-predicted from

242 simulations based on individual consumption (Fig. 2b), and thus prey risk was additive here as predator density increased. At the greater depth, functional responses were more similar between predators (Fig. 2c), with confidence intervals overlapping at intermediate-high prey densities. In turn, simulations of multiple predator functional responses were not significantly different to those observed experimentally under the greater depth (Fig. 2d). Thus, additive multiple predator effects between the copepod predators were observed across both levels of water depth. Nevertheless, predictions of multiple predator functional responses tended to be more similar to those observed under the greater water depth.

\section{Discussion}

The two key arid-area adapted specialist predatory copepods, L. raynerae and P. lamellatus, displayed additive multiple predator effects irrespective of water depth in the present study. As such, larval mosquito prey risk was predictable from simulations based on individual predator functional response parameters. Nevertheless, significant differences in predatory impact were exhibited between predators, with L. raynerae overall significantly more voracious than $P$. lamellatus. This finding corroborates with a previous comparative functional response study between the two copepod species individually towards cladoceran prey (Wasserman et al., 2016a), and stable isotope analysis whereby P. lamellatus was suggeted to be a less predaceous than L. raynerae (Dalu et al., 2017). These consumptive 
be less affected by variations in water depth than L. raynerae. Although these species are considered pioneers which hatch relatively early in the hydroperiod, they often persist to the end of a pond's wet phase (Dalu et al., 2016). Therefore, our results are applicable to various hydroperiod stages, with additive multiple predator effects driving increases in prey risk synonymous with predator abundances in these systems.

The feeding magnitude of gravid female L. raynerae in the present study was shown to be significantly higher than gravid $P$. lamellatus, irrespective of prey density and water depth. Gravid female paradiaptomid copepods may be more voracious than males or non-gravid females, influencing population-level interaction strengths (Cuthbert et al., 2019c). Interspecific differences in predatory efficiences between L. raynerae and P. lamellatus appear to persist across sex demographics, as Wasserman et al. (2016b) demonstrated greater functional response magnitudes of adult male L. raynerae over P. lamallatus. This consumptive difference suggests that $L$. raynerae contributed most substantially to observed predation rates in multiple predator groups. Furthermore, the lack of significant influence of water depth (i.e. search area) on interaction strengths in the present study suggests that high predation rates may be sustained thoughout different pond water volumes during the hydroperiod. This corroborates with the time-stresses associated with maturation and reproduction during short hydroperiods. Nevertheless, increasing depth tended to relate negatively to consumption overall, and this effect may become more pronounced under greater expermental depths than tested here. Further, although the extrapolation of laboratory results to empirical systems should be viewed with caution, comparative functional response studies such as the present can provide useful pheneomenological insights as to the effects of environmental heterogeniety on interaction strengths (Jeschke et al., 2002; Dick et al., 2014), and particularly in austral temporary wetland ecosystems where little autoecological information currently exists. 
Functional response form was unchanged across predator groups in the present study, with Type II models providing the best fit to the data. The functional response of P. lamellatus was, however, more equivocal in comparison to L. raynerae, with asymptopic declines in consumption rates less marked. Wasserman et al. (2016b) found similarly equivocal results between these species; however, in the present study, the categorical model minimised information loss as compared to generalised forms of the functional response (see Pritchard et al., 2017). This is also reflected in the considerable differences in attack rates between the two species, with $L$. raynerae exhibiting a substantially higher attack coefficient. This may be driven by higher encounter rates with prey, owing to the foraging behaviour of L. raynerae in the open water. As attack rates correspond to the initial slope of functional response curves (see Cuthbert et al., 2019d), high attack rates can be particularly destabilising to prey populations at low densities. Accordingly, differences in predator hatching phenology from egg banks in temporary wetlands may promote prey stability if community composition favours high abundances of $P$. lamellatus over L. raynerae. Little is currently known about environmental drivers that influence hatching success in austral temporary systems (but see Mabidi et al., 2018), with many temporary-water inhabitants employing temporal bet hedging strategies (Brendonck et al., 1998).

Copepods are present in most aquatic systems and often provide an important link between trophic groups (i.e. from primary producers to predators) (Naganuma, 1996; Calbet and Saiz, 2005). In previous studies, copepods have been shown to exhibit all three classic functional response forms (Paffenhöfer and Stearns, 1988; Hooff and Bollens, 2004; Jeschke et al., 2004; Cuthbert et al., 2019a). While many freshwater copepods exhibit Type I functional responses, this linear feeding response is mechanistically restricted to filter feeders, with predatory copepods such as those in the present study subject to prey handling restraints which cause asymptotic consumption declines with increasing prey densities (Jeschke et al., 

compared to L. raynerae in the present study, with the latter species displaying substantially higher maximum feeding rates. However, difference in feeding magnitude tended to be less pronounced at the higher water depth between species, suggesting that L. raynerae is more substantially impacted by changes in water depth, and thus search area, over the hydroperiod. As L. raynerae is an active forager through the entire water column, alterations to water volume likely drive differences in encounter rates for this species. By contrast, P. lamellatus, as a hyperbenthic feeder, may be less affected by changes in water depth. The spatial partitioning of these two key predatory copepods within aquatic habitats may limit the potential for interspecific multiple predator effects which alter prey risk (see Schmitz, 2007), with multiple predators shown to impact prey independently in the present study. The additive multiple predator interaction found here corroborates with other studies on freshwater crustaceans, where predator feeding rates also appear to combine independently under certain conditions (Barrios-O’Neill et al., 2014). Accordingly, in temporary wetland ecosystems, greater predator diversity likely does not result in significant alterations to prey risk. Furthermore, given the potential importance of paradiaptomid copepods for the regulation of vectorially-efficient mosquito species (see Cuthbert et al., 2018a), additive multiple predator effects may further assist with the natural regulation of pests and disease. As the coexistence of L. raynerae and P. lamellatus is common in austral temporary ponds in their native range, our results contribute important information on the trophic dynamics of these systems where little autoecological information currently exists. Predator diversity is thus likely an important component that heightens interaction strengths in these aquatic habitats. 
This study was funded by the Department for the Economy, Northern Ireland. We extend gratitude to Rhodes University for the provision of laboratory facilities. We acknowledge use of infrastructure and equipment provided by the South African Institute for Aquatic Biodiversity (SAIAB) Research Platform and the funding channelled through the National Research Foundation - SAIAB Institutional Support system. This study was partly funded by the National Research Foundation - South African Research Chairs Initiative of the Department of Science and Technology (Inland Fisheries and Freshwater Ecology, Grant No. 110507). TD is supported by the National Research Foundation Thuthuka Grant (No. 117700).

\section{References}

Alexander, M.E., Dick, J.T.A., O’Connor, N.E., Haddaway, N.R., Fansworth, K.D., 2012. Functional responses of the intertidal amphipod Echinogammarus marinus: effects of prey supply, model selection and habitat complexity. Mar. Ecol. Prog. Ser. 468, 191202.

Barrios-O’Neill, D., Dick, J.T.A., Emmerson, M.C., Ricciardi, A., MacIsaac, H.J., Alexander, M.E., Bovy, H.C., 2014. Fortune favours the bold: a higher predator reduces the impact of a native but not an invasive intermediate predator. J. Anim. Ecol. 83, 693- 
Beddington, J.R., 1975. Mutual interference between parasites or predators and its effect on searching efficiency. J. Anim. Ecol. 44, 331-340.

Bolker, B.M., 2008. emdbook: Ecological models and data in R, R Package. Princeton University Press, Princeton.

Bolker, B.M., Holyoak, M., Křivan, V., Rowe, L., Schmitz, O., 2003. Connecting theoretical and empirical studies of trait-mediated interactions. Ecology 84, 1101-1114.

Brendonck, L., De Meester, L., 2003. Egg banks in freshwater zooplankton: evolutionary and ecological archives in the sediment. Hydrobiologia 491, 65-84.

Brendonck, L., Riddoch, B.J., Van de Weghe, V., Van Dooren, T.,1998. The maintenance of egg banks in very short lived pools - a case study with anostracans (Branchiopoda). Arch. Hydrobiol. 52, 141-161.

Burnham, K.P., Anderson, D.R., 2002. Model selection and multimodel inference. A practical information-theoretic approach. Springer, New York.

Calbet, A., Saiz, E., 2005. The ciliate-copepod link in marine ecosystems. Aquat. Microb. Ecol. 38, 157-167.

Cuthbert, R.N., Callaghan, A., Dick, J.T.A., 2019a. The effect of the alternative prey, Paramecium caudatum (Peniculida: Parameciidae), on the predation of Culex pipiens (Diptera: Culicidae) by the copepods Macrocyclops albidus and Megacyclops viridis (Cyclopoida: Cyclopidae). J. Med. Entomol. 56, 276-279.

Cuthbert, R.N., Callaghan, A., Sentis, A., Dalal, A., Dick, J.T.A., 2019b. Additive multiple predator effects can reduce mosquito populations. Ecol. Entomol. in press. 
Cuthbert, R.N., Dalu, T., Wasserman, R.J., Callaghan, A., Weyl, O.L.F., Dick, J.T.A., 2018a. Calanoid copepods: an overlooked tool in the control of disease vector mosquitoes. J. Med. Entomol. 25, 1656-1658.

Cuthbert, R.N., Dalu, T., Wasserman, R.J., Weyl, O.L.F., Callaghan, A., Froneman, P.W., Dick, J.T.A., 2019c. Sex-skewed trophic impacts in temporary wetlands. Freshwater Biol. 64, 359-366.

Cuthbert, R.N., Dickey, J.W.E., Coughlan, N.E., Joyce, P.W.S., Dick, J.T.A., 2019d. The Functional Response Ratio (FRR): advancing comparative metrics for predicting the ecological impacts of invasive alien species. Biol. Invasions in press.

Dalu, T., Wasserman, R.J., Vink, T.J.F., Weyl, O.L.F., 2017. Sex and species specific isotopic niche specialisation increases with trophic complexity: evidence from an temporary pond ecosystem. Sci. Rep. 7, 43229.

Dalu, T., Weyl, O.L.F., Froneman, P.W., Wasserman, R.J., 2016. Trophic interactions in an Austral temperate temporary pond inferred using stable isotope analysis. Hydrobiologia 768, 81-94.

Day, J.A., De Moor, I.J., Stewart, B.A., Louw, A.E., 2001. Guides to the freshwater invertebrates of Southern Africa. Vol 3: Crustacea II. Ostracoda, Copepoda and Branchiura. Report No. TT148/01. Water Research Commission, Pretoria.

Dick, J.T.A., Alexander, M.E., Jeschke, J.M., Ricciardi, A., MacIsaac, H.J., Robinson, T.B., Kumschick, S., Weyl, O.L.F., Dunn, A.M., Hatcher, M.J., Paterson, R.A., Farnsworth, K.D., Richardson, D.M., 2014. Advancing impact prediction and hypothesis testing in invasion ecology using a comparative functional response approach. Biol. Invasions 16, 735-753. 
Fox, J., Weisberg, S., 2011. An R companion to applied regression. Sage, Thousand Oaks.

405

406

407

408

409

410

411

412

413

414

415

416

417

418

419

420

421

422

423

424

425

Griffen, B.D., 2006. Detecting emergent effects of multiple predator species. Oecologia 148, 702-709.

Hassell, M.P., 1978. The dynamics of arthropod predator-prey systems. Princeton University Press, Princeton.

Holling, C.S., 1959. Some characteristics of simple types of predation and parasitism. Can. Entomol. 91, 385-398.

Hooff, R.C., Bollens, S.M., 2004. Functional response and potential predatory impact of Tortanus dextrilobatus, a carnivorous copepod recently introduced to the San Francisco Estuary. Mar. Ecol. Progr. Ser. 277, 167-179.

Jeschke, J.M., Kopp, M., Tollrian, R., 2002. Predator functional responses: discriminating between handling and digesting prey. Ecol. Monogr. 72, 95-112.

Jeschke, J.M., Kopp, M., Tollrian, R., 2004. Consumer-food systems: why type I functional responses are exclusive to filter feeders. Biol. Rev. 79, 337-349.

Johnson, P.T.J., Olden, J.D., Solomon, C.T., Vander Zanden, M.J., 2009. Interactions among invaders: community and ecosystem effects of multiple invasive species in an experimental aquatic system. Oecologia 159, 161-170.

Juliano, S.A., 2001. Non-linear curve fitting: predation and functional response curves, In: Scheiner, S.M., Gurevitch, J. (Eds.), Design and analysis of ecological experiments. Oxford University Press, Oxford, pp. 178-196.

Lampropoulos, P.D., Perdikis, D.C., Fantinou, A.A., 2013. Are multiple predator effects directed by prey availability? Basic Appl. Ecol. 14, 605-613. 
Lenth, R., 2018. emmeans: estimated marginal means, aka least-squares means. R package.

427

428

429

430

Losey, J.E., Denno, R.F., 1998. Positive predator - predator interactions: enhanced predation rates and synergistic suppression of aphid populations. Ecology 79, 2143-2152.

Lynch, M., 1979. Predation, competition, and zooplankton community structure: an experimental study. Limnol. Oceanogr. 24, 253-272.

Mabidi, A., Bird, M. S., Perissinotto, R. 2018. Increasing salinity drastically reduces hatching success of crustaceans from depression wetlands of the semi-arid Eastern Cape Karoo region, South Africa. Sci Rep., 8, 5983.

McCoy, M.W., Stier, A.C., Osenberg, C.W., 2012. Emergent effects of multiple predators on prey survival: the importance of depletion and the functional response. Ecol. Lett. 15, 1449-1456.

Mofu, L., South, J., Dalu, T., Wasserman, R.J., Woodford, D.J., Weyl, O.L.F., 2019. Interspecific differences in invader and native fish functional responses illustrate neutral effects on prey but superior invader competitive ability. Freshwater Biol. in press.

Naganuma, T., 1996. Calanoid copepods: Linking lower-higher trophic levels by linking lower-higher Reynolds numbers. Mar. Ecol. Prog. Ser. 136, 311-313.

Neill, W.E., 1990. Induced vertical migration in copepods as a defence against invertebrate predation. Nature 345, 524-526.

O’Neill, B.J., Thorp, J.H., 2014. Untangling food-web structure in an temporary ecosystem. Freshwater Biol. 59, 1462-1473.

Paffenhőfer, G.-A., Stearns, D.E., 1988. Why is Acartia tonsa (Copepoda: Calanoida) restricted to nearshore environments? Mar. Ecol. Progr. Ser. 42, 33-38. 
449 Paine, R.T., 1980. Food webs: linkage, interaction strength and community infrastructure. J.

450

451

452

453

454

455

456

457

458

459

460

461

462

463

464

465

466

467

468

469 Anim. Ecol. 49, 667-685.

Polis, G.A., Myers, C.A., Holt, R.D., 1989. The ecology and evolution of intraguild predation: potential competitors that eat each other. Annu. Rev. Ecol. Syst. 20, 297330.

Pritchard, D.W., Paterson, R.A., Bovy, H.C., Barrios-O’Neill, D., 2017. Frair: an R package for fitting and comparing consumer functional responses. Methods Ecol. Evol. 8, $1528-1534$.

R Core Development Team., 2018. R: a language and environment for statistical computing. Vienna.

Real, L.A., 1977. The kinetics of functional response. Am. Nat. 111, 289-299.

Rogers, D., 1972. Random search and insect population models. J. Anim. Ecol. 41, 369-383.

Schmitz, O.J., 2007. Predator diversity and trophic interactions. Ecology 88, 2415-2426.

Sentis, A., Boukal, D.S., 2018. On the use of functional responses to quantify emergent multiple predator effects. Sci. Rep. 8, 11787.

Sentis, A., Gémard, C., Jaugeon, B., Boukal, D.S., 2017. Predator diversity and environmental change modify the strengths of trophic and nontrophic interactions. Glob. Change Biol. 23, 2629-2640.

Sih, A., Crowley, P., McPeek, M., Petranka, J., Strohmeier, K., 1985. Predation, competition and prey communities: a review of field experiments. Annu. Rev. Ecol. Syst. 16, 269311. 
Sih, A., Englund, G., Wooster, D., 1998. Emergent impacts of multiple predators on prey. Trends Ecol. Evol. 13, 350-355.

Soetaert, K., Petzoldt, T., 2010. Inverse modelling, sensitivity and Monte Carlo analysis in R using package FME. J. Stat. Softw. 33, 1-28.

Soluk, D.A., 1993. Multiple predator effects: predicting combined functional response of stream fish and invertebrate predators. Ecology 74, 219-255.

Suárez-Morales, E., Wasserman, R.J., Dalu, T., 2015. A new species of Lovenula Schmeil (Copepoda, Calanoida, Diaptomidae) from the Eastern Cape Province of South Africa. Crustaceana 88, 324-342.

Thompson, J.N., 2005. Coevolution: the geographic mosaic of coevolutionary arms races. Curr. Biol. 15, 992-994.

Trexler, J.C., McCullough, C.E., Travis, J., 1988. How can the functional response best be determined? Oecologia 76, 206-214.

Uiterwaal, S.F., DeLong, J.P., 2018. Multiple factors, including arena size, shape the functional responses of ladybird beetles. J. Appl. Ecol. 55, 2429-2438.

Veselý, L., Boukal, D.S., Buřič, M., Kuklina, I., Fořt, M., Yazicioglu, B., Prchal, M., Kozák, P., Kouba, A., Sentis, A., 2019. Temperature and prey density jointly influence trophic and non-trophic interactions in multiple predator communities. Freshwater Biol. in press.

Veselý, L., Boukal, D. S., Buřič, M., Kozák, P., Kouba, A., Sentis, A., 2017. Effects of prey density, temperature and predator diversity on nonconsumptive predator-driven mortality in a freshwater food web. Sci. Rep. 7, 18075. 
Vucic-Pestic, O., Rall, B. C., Kalinkat, G., Brose, U., 2010. Allometric functional response model: body masses constrain interaction strengths. J. Anim. Ecol. 79, 249-256.

Wasserman, R.J., Alexander, M.E., Barrios-O’Neill, D., Weyl, O.L.F., Dalu, T., $2016 a$. Using functional responses to assess predator hatching phenology implications for pioneering prey in arid temporary pools. J. Plank. Res. 38, 154-158.

Wasserman, R.J., Alexander, M.E., Dalu, T., Ellender, B.R., Kaiser, H., Weyl, O.L.F., $2016 b$. Using functional responses to quantify interaction effects among predators. Funct. Ecol. 30, 1988-1998.

Wasserman, R.J., Noyon, M., Avery, T.S., Froneman, P.W., 2013. Trophic level stabilityinducing effects of predaceous early juvenile fish in an estuarine mesocosm study. PLOS One 8, e61019.

Wasserman, R.J., Weston, M., Weyl, O.L.F., Froneman, P.W., Welch, R.J., Vink, T.J., Dalu, T., 2018. Sacrificial males: the potential role of copulation and predation in contributing to copepod sex-skewed ratios. Oikos 127, 970-980. 
513 Table 1. Functional response parameter estimates across predator treatments and between

514 water depths. First-order terms are estimated from logistic regression of prey mortality rates

515 from consumption as a function of density, whilst attack rate and handling time estimates are

516 discerned from the random predator equation.

\begin{tabular}{|c|c|c|c|c|c|}
\hline Predator(s) & Depth & $\begin{array}{l}\text { First-order } \\
\text { term, } p\end{array}$ & Attack rate, $p$ & $\begin{array}{l}\text { Handling } \\
\text { time, } h\end{array}$ & $\begin{array}{l}\text { Maximum } \\
\text { feeding rate, } \\
1 / h\end{array}$ \\
\hline L. raynerae & 40 & $-0.08,<0.001$ & $4.52,0.005$ & $0.07,<0.001$ & 13.86 \\
\hline P. lamellatus & 40 & $-0.03,0.14$ & $0.37,0.05$ & $0.16,0.10$ & 9.66 \\
\hline $\begin{array}{l}\text { L. raynerae }+ \\
\text { P. lamellatus }\end{array}$ & 40 & $-0.07,<0.001$ & $4.38,0.004$ & $0.08,<0.001$ & 13.32 \\
\hline L. raynerae & 80 & $-0.08,<0.001$ & $5.38,0.06$ & $0.11,<0.001$ & 8.95 \\
\hline P. lamellatus & 80 & $-0.01,0.50$ & $0.18,0.04$ & $0.09,0.49$ & 10.93 \\
\hline $\begin{array}{l}\text { L. raynerae }+ \\
\text { P. lamellatus }\end{array}$ & 80 & $-0.06,<0.001$ & $2.44,<0.001$ & $0.07,<0.001$ & 14.37 \\
\hline
\end{tabular}

517

518

519

520

521 


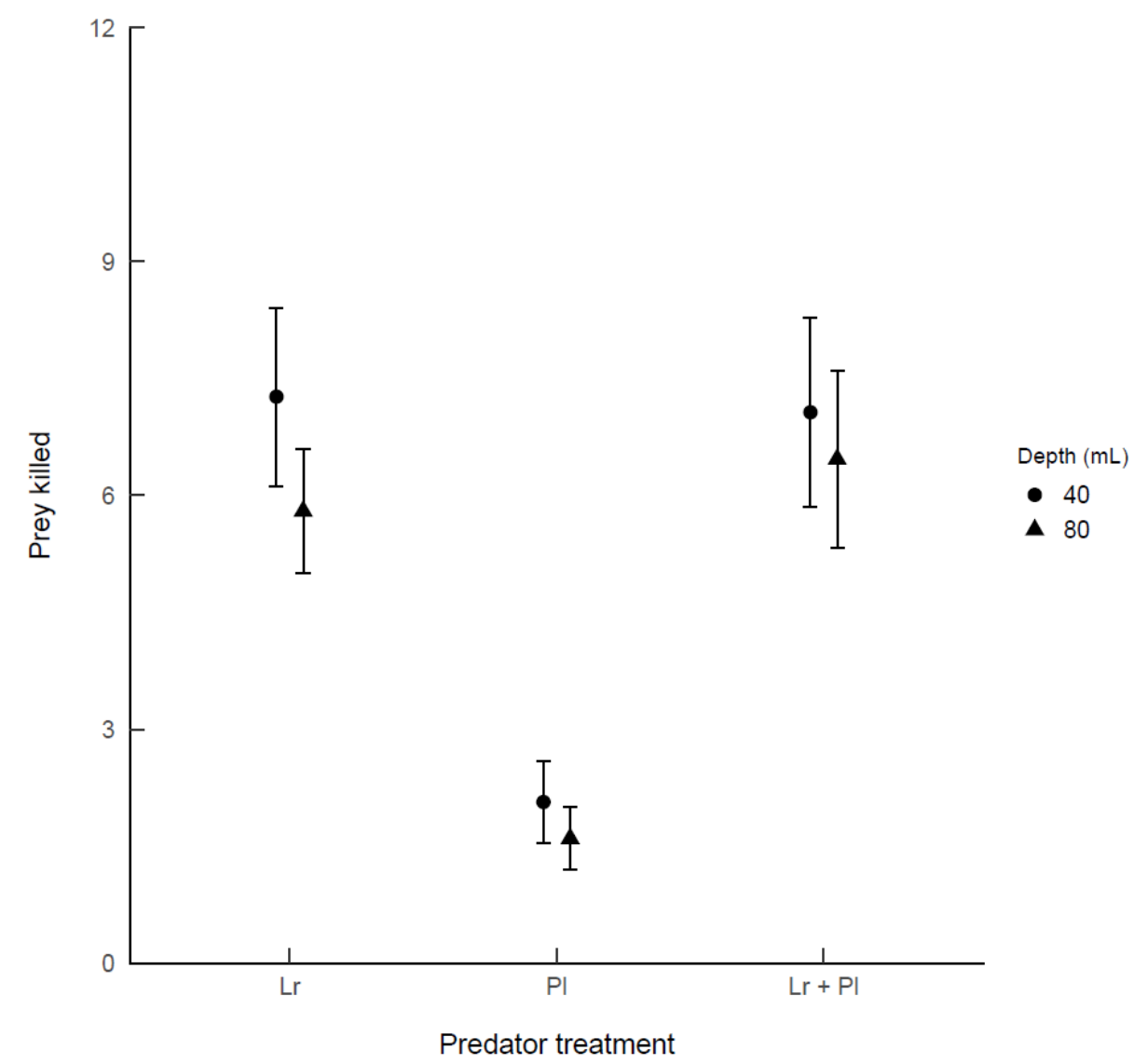

524 Fig. 1. Mosquito prey mortality from consumption under different predator treatments

525 (Lovenula raynerae, $\mathrm{Lr} ;$ Paradiaptomus lamellatus, $\mathrm{Pl} ;$ L. raynerae + P. lamellatus, $\mathrm{Lr}+\mathrm{Pl}$ )

526 and between water depths. Means are \pm 1 SE, pooled across all prey densities. 


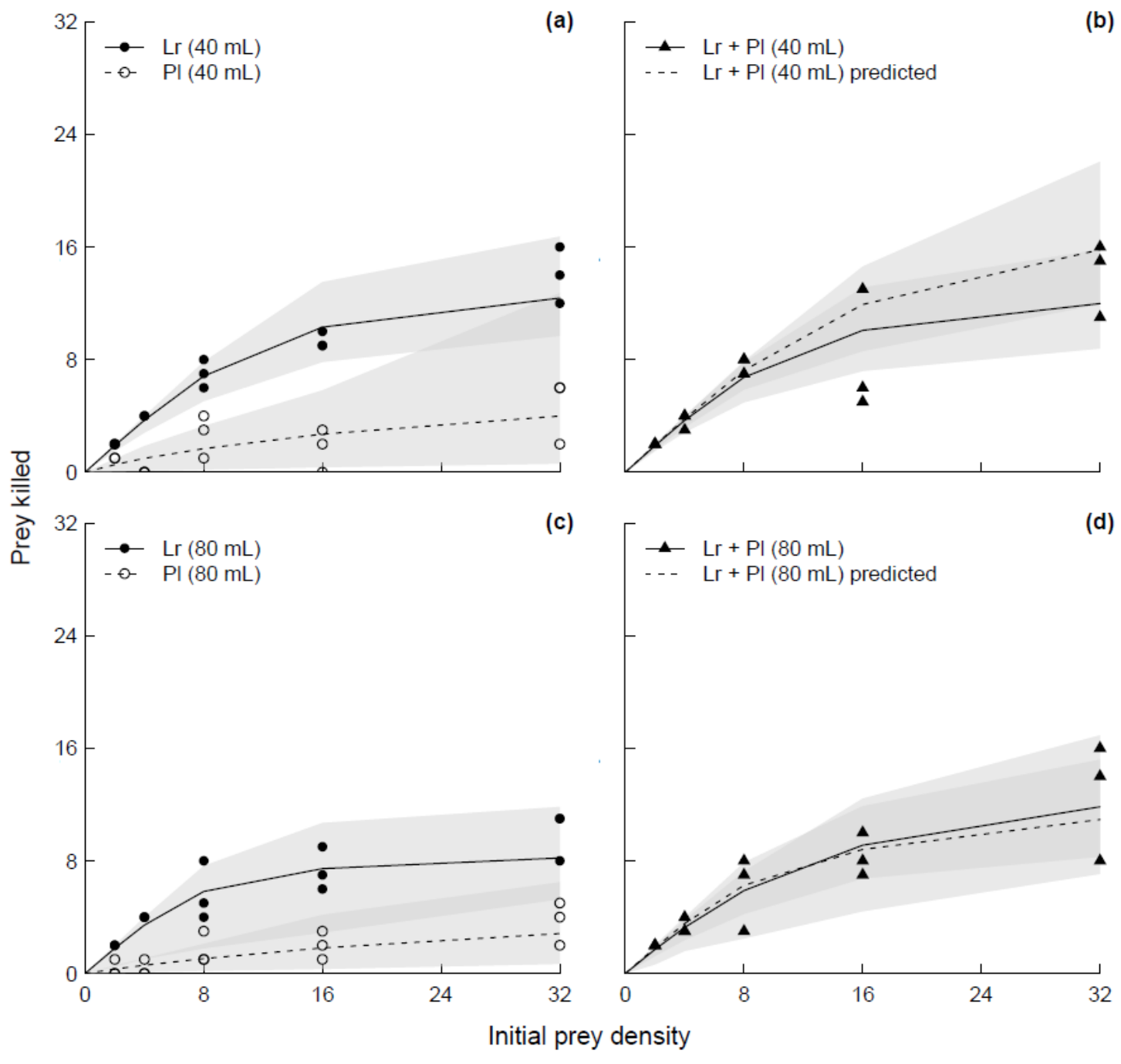

527

528 Fig. 2. Copepod functional responses considering mosquito prey mortality from consumption

529 under different predator treatments (Lovenula raynerae, Lr; Paradiaptomus lamellatus, $\mathrm{Pl} ; L$.

530 raynerae $+P$. lamellatus, $\mathrm{Lr}+\mathrm{Pl})$ and between water depths $(40 \mathrm{~mL}: \mathrm{a}, \mathrm{b} ; 80 \mathrm{~mL}: \mathrm{c}, \mathrm{d})$. The

531 left panels (a, c) display per capita feeding rates and the right panels total multiple predator

532 feeding rates. Predictions of multiple predator feeding rates (b, d) are simulated based on

533 individual consumption rates at corresponding depths $(\mathrm{a}, \mathrm{c})$ over the total experimental period

534 (i.e. 4 h). Points are raw data and shaded areas are $95 \%$ confidence intervals. 